\title{
AC 2012-3641: FRESHMEN RESEARCH PROJECT: DESIGN, DEVEL- OPMENT, AND TESTING OF VARIABLE PITCH PROPELLER THRUST MEASUREMENT APPARATUS - A CASE STUDY
}

Dr. Adeel Khalid, Southern Polytechnic State University

Adeel Khalid, Ph.D., Assistant Professor Systems Engineering Program, Division of Engineering, Q-349, Southern Polytechnic State University, 1100 South Marietta Parkway, Marietta, GA 30060, Office: 678-

915-7241; Fax: 678-915-5527; Web: http://www.spsu.edu/systemseng/adeel_khalid.htm; http://www.spsu.edu/aerospace/. 


\title{
Freshmen Research Project: Design, Development and Testing of Variable Pitch Propeller Thrust Measurement Apparatus - A Case Study
}

\begin{abstract}
$\underline{\text { Abstract }}$
When students first start their engineering education, they often do not know what to expect in terms of the curriculum. Students are often discouraged by the rigor of freshmen theoretical courses. One of the ways to motivate them and keep them interested in engineering is to have them work on hands on projects. In this project, freshmen students designed, developed, and tested a variable pitch propeller apparatus. The apparatus was intended to become a part of the aerospace engineering laboratory that future students would use to conduct experiments. The challenges of working with freshmen engineering students are discussed and lessons learned are outlined.
\end{abstract}

\section{Introduction}

The challenges associated with getting freshmen students involved in research studies mirror those of graduate level research. Often time undergraduate students are less prepared for a research study. They are looking for an experience as a means to determine career pathways. The support mechanisms, evaluation structure, and reward systems for undergraduate students are not well established or well defined and are still being developed in many institutions and disciplines. In addition, funding mechanisms have not truly figured out how to properly evaluate and fund undergraduate research ${ }^{1,2}$. Given those challenges, it is still important to get them motivated and interested in the research in the discipline of their choice ${ }^{3}$. In this project, with the help of a case study, few of the challenges of undergraduate research are discussed. Methods used to overcome those challenges are outlined.

The goal of this research project is to design, develop, and test an inexpensive thrust measurement apparatus and get freshmen undergraduate engineering students involved in the research. A variable pitch propeller is used to study the effect of changing pitch on the thrust. Some of the other variables studied include the blade rotational speed, rotor chord, span, twist and taper ratio. Motor speed and propeller pitch are controlled by separate electronic speed controllers. The effect of other variables i.e. rotor blade chord, span, twist, and taper ratio are studied by using separate blades of various specifications. Blades are designed using a Computer Aided Design (CAD) package i.e. Solid Works, and printed using 3D printer. The apparatus is designed to be robust enough to be used as laboratory equipment for future undergraduate students to conduct research projects and laboratory experiments in conjunction with their aerospace courses. The apparatus will help students understand the principles of thrust and how various variables affect the thrust produced by propeller driven aircraft. The goal is to develop 
the entire system for minimum cost. Students get experience in designing the mechanical hardware, electrical hardware and software. Students conducting the experiments will be able to determine how the thrust varies as a function of the design parameters. Variable pitch propeller concept is used in single and multi-engine propeller aircraft, and turbine engine compressor blades. Undergraduate freshmen Peach State LSAMP (Louis Stokes Alliance for Minority Participation) students participated in this summer research project and decided to continue to work after the program was over. The design details, challenges, results and lessons learnt are discussed in the paper.

\section{Motivation}

The motivation of this project is to impart new and advanced knowledge and understanding to undergraduate students. This will inspire students and help them comprehend and respond to diverse and fast changing knowledge and technologies in Aerospace domain. This initiative is inline with the development of a new Aerospace engineering program at Southern Polytechnic State University. The research skills obtained by undergraduate students in their early education careers are an important learning experience. Special emphasis is put on design, practice, integration, and application of the scientific and technical knowledge learned from the classroom through various activities. The topic chosen for research is rather simple yet important to understand. It has real world applications. It provides analytical and experimental knowledge and skills to the students involved. This endeavor provided a great opportunity to gain the depth of knowledge for students by planning, initiating, and conducting research in engineering principles. As the mentor of undergraduate research students, the author believes that students get a reasonable opportunity to complete their project within a given time while producing reasonable and useful results. Attention is paid during the project to each student's level in terms of interest, knowledge, ability and capacity. Students learn theoretical and experimental knowledge of pursuing applied engineering research using critical and creative thinking, problem-solving, and trouble-shooting skills.

\section{The Peach State LSAMP Summer Fellowship Program}

The Peach State Louis Stokes Alliance for Minority Participation (LSAMP) program is designed for underrepresented minority students. It is a collaborative effort sustained by five higher education institutions in the state of Georgia ${ }^{6}$. These include:

- Southern Polytechnic State University (SPSU)

- Fort Valley State University

- Georgia Perimeter College

- Savannah State University

- University of Georgia 
At SPSU, it provides scholars supplemental instruction and an opportunity for academic enrichment. It promotes learning communities amongst fresh engineering students. It also provides opportunities for tutoring, financial support, peer and faculty mentoring, STEM conferences, research opportunities, summer bridge program, leadership development, outreach initiatives, and internships ${ }^{6}$. The project also exposes students to topics not covered elsewhere in the curriculum such as the business aspect of engineering and its impact on design ${ }^{8}$. Students are selected based on a set of academic criteria. To be eligible, a student must plan to major in Science, Technology, Engineering, or Math (STEM) subjects. The goal of the Alliance is ${ }^{5}$ :

“...to substantially increase the number of underrepresented minority students who pursue and graduate with Baccalaureate Degrees in Science, Technology, Engineering, and Mathematics (STEM). Since November 1992, the appliance has been at the forefront of a concerted effort to increase annual Minority STEM enrollment and graduation in community..."

“...LSAMP support research training opportunities and academic support services for students to encourage greater participation in Science, Technology, Engineering and Mathematics (STEM), and to boost academic excellence..."

The Peach State LSAMP research assistantship is a competitive award given based on student's overall GPA, academic achievement in standardized tests (SAT), and the recommendation of their faculty advisor. The Peach State LSAMP summer fellowship program requires students to attend all meetings, regularly attend research seminars indicated by their faculty mentor, and participate in the annual Peach State LSAMP conference. Students are also required to submit progress and final reports on their research. The final presentation at the annual conference is essential at the end of the summer program - it gives students the opportunity to present their results in front of their peers and other students and faculty from participating institutions.

\section{Procedure for Peach State LSAMP Undergraduate Research}

The procedure for initiating the undergraduate research required several steps. The first step was the preparation of the idea or topic for the project. At this step, we identified and listed the students' interest in possible research topics. A short presentation was made to introduce all the students to the idea. During the introduction presentation, the mission statement, goals, and objectives were defined for the project. Students were recruited based on their level of interest, knowledge, ability and capacity. A timetable was established to complete the project. The timetable is shown in the form of a Gantt chart in Table 1. This provided students guidelines to stay on track. Students also completed design documentation using systems engineering approach $^{9}$. Specific emphasis was given on project management such as to meet various deadlines. Gantt chart was used to keep track of project activities. The idea was to make the equipment part of the Aerospace laboratory which was being established as part of the new Aerospace program at SPSU. The laboratory space had not yet been identified, so storage of equipment and materials was a challenge. 
Table1: Schedule for Summer Peach State LSAMP Research: Design of Variable Pitch Propeller Apparatus

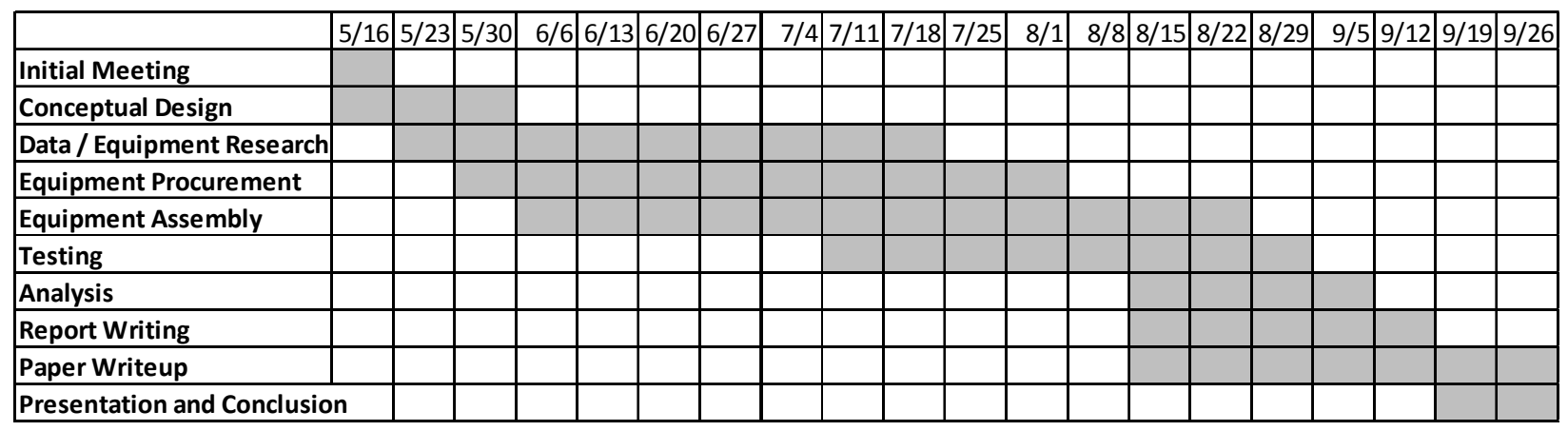

After the initial meeting, the rules, procedures, and guidelines specific to Peach State LSAMP program were identified. A small group of students was selected to conduct the research. Background information was provided to the students. Students were required to perform literature review to investigate whether similar projects had been developed. Weekly meetings were scheduled and students were required to show progress and discuss problems. Students were also given brief informal lectures to improve their theoretical knowledge and hand-on experimental skills. The project activities were routinely evaluated and student feedback was collected. Students were challenged with finding and acquiring equipment to be used in the apparatus. They were then tasked with coming up with various configurations of the apparatus and selecting the one that best satisfied the requirements. At the same time, students were encouraged to write technical report and prepare a presentation file for all the work done. Students were also guided in terms of preparing and presenting the research. They presented their work in seminars in front of their peers to collect feedback. Students were finally required to present their work at the state wide annual Peach State LSAMP conference. Student evaluations and other feedback was collected before the end of the summer project.

\section{$\underline{\text { Thrust Measurement Apparatus Description }}$}

The purpose of development of this apparatus was to help students understand how the thrust generated by a propeller varies as a function of various factors. These variables include the following:

- $\quad$ Speed

- Span

- Chord

- Twist

- Pitch

- Taper Ratio 
By changing these variables, an optimum amount of thrust could be obtained. The thrust generated by the propeller is determined by its area, fluid density, velocity, and the angle of attack of the airfoil ${ }^{7}$.

$$
\begin{gathered}
L=\frac{1}{2} \rho V^{2} C_{L} S \\
C_{L}=a \cdot \alpha
\end{gathered}
$$

Where

$L=$ Thrust Developed by the Propeller

$$
\rho=\text { Density of Air }
$$

$S=$ Area of Propeller Blades

$a=$ Lift Curve Slope

$C_{L}=$ Lift Coefficient

$\alpha=$ Angle of Attack (pitch)

$V=$ Wind Velocity in Propeller Slip Stream

Area of the propeller blade is a function of the chord and span. The lift or the thrust produced by the propeller is proportional to the square of the speed. It varies linearly with all the other parameters of interest. The variable pitch propeller is used in small single engine general aviation aircraft and in large turbo prop heavy lift aircraft. To help students study and understand these concepts, the apparatus was designed where the propeller was mounted on a truck bed that rolls over a platform. The truck bed was attached with a stationary digital force measurement scale. As the thrust increases, the truck bed moves and the amount of thrust being produced by the propellers is measured using the scale. The conceptual design is shown in Figure 1. 


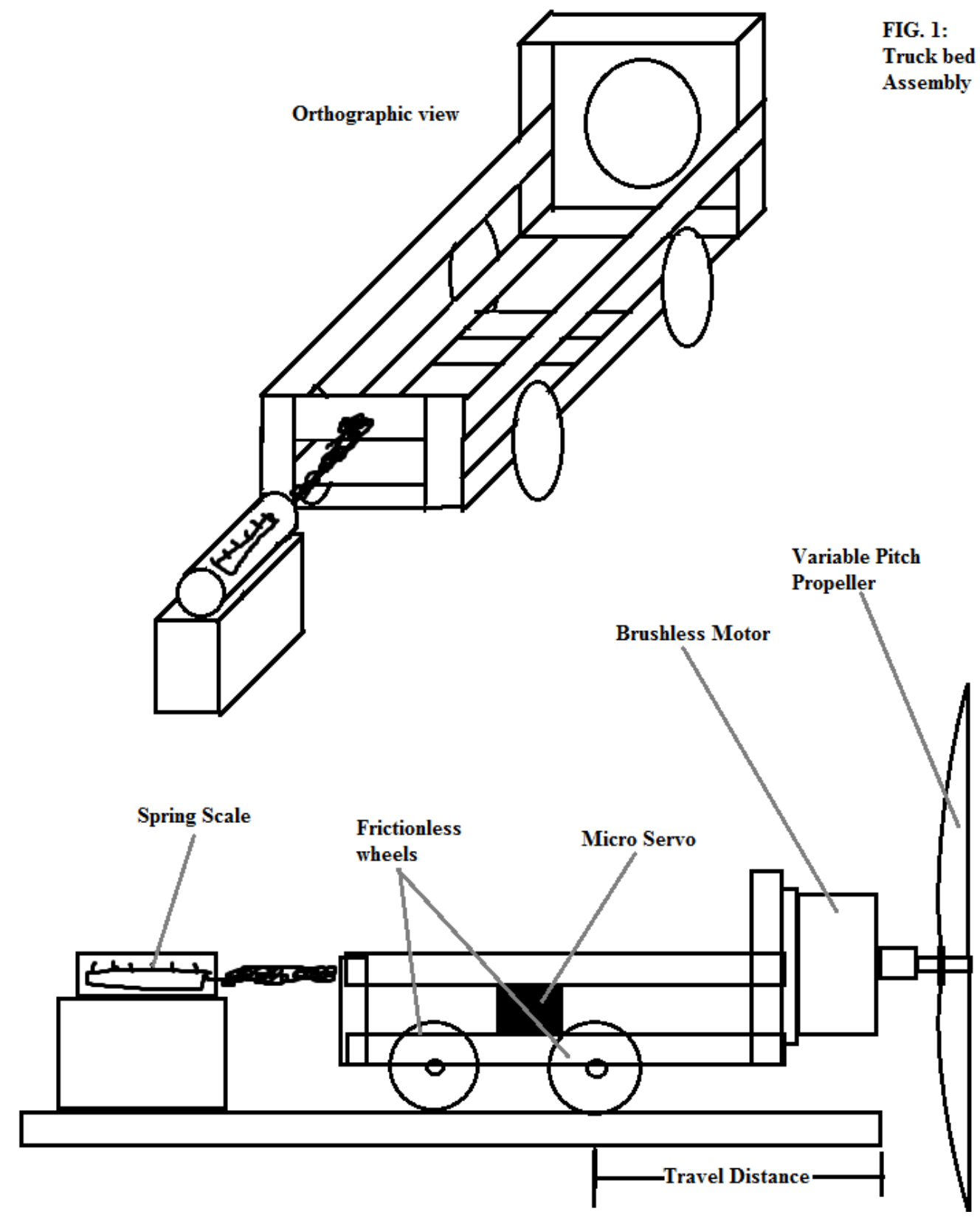

Figure 1: Conceptual Design of the Thrust Measurement Apparatus

The operator can mount various types of propellers. Propellers are designed using Computer Aided Design (CAD) software called Solid Works ${ }^{\circledR}$. These include propellers of various spans, chords, taper ratios and twists. An orthogonal view of the propellers is shown in Figure 2. The author believes that exposure to such CAD tools allows the students to experience the latest aircraft design tools and prepares them for the appropriate careers ${ }^{8}$. 


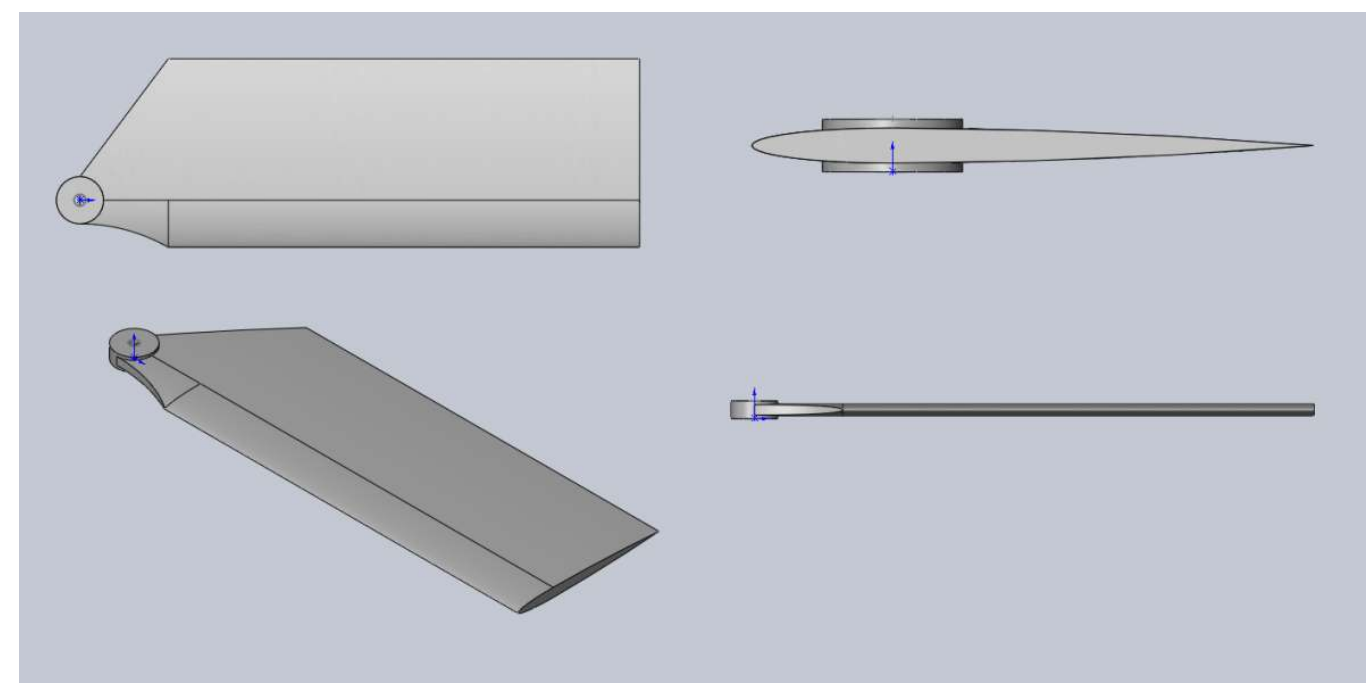

Figure 2: Orthogonal views of the propellers designed using CAD
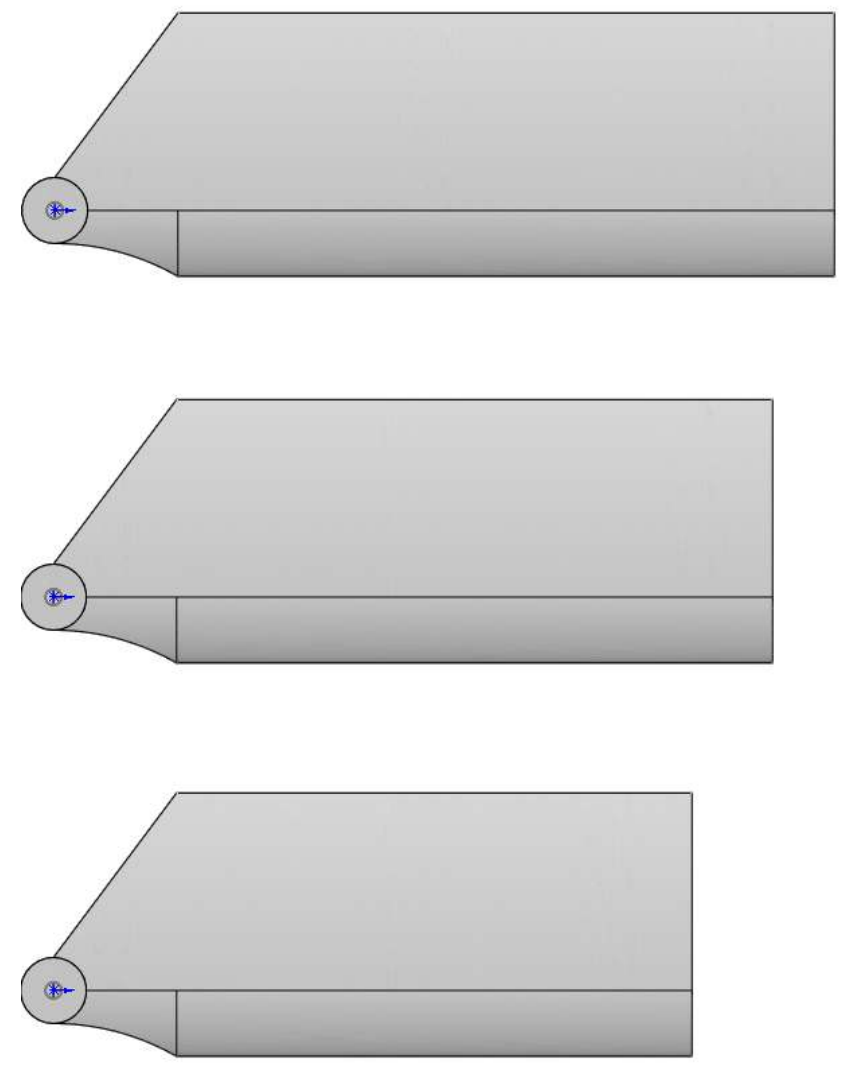

Figure 3: Propellers of varying Spans 

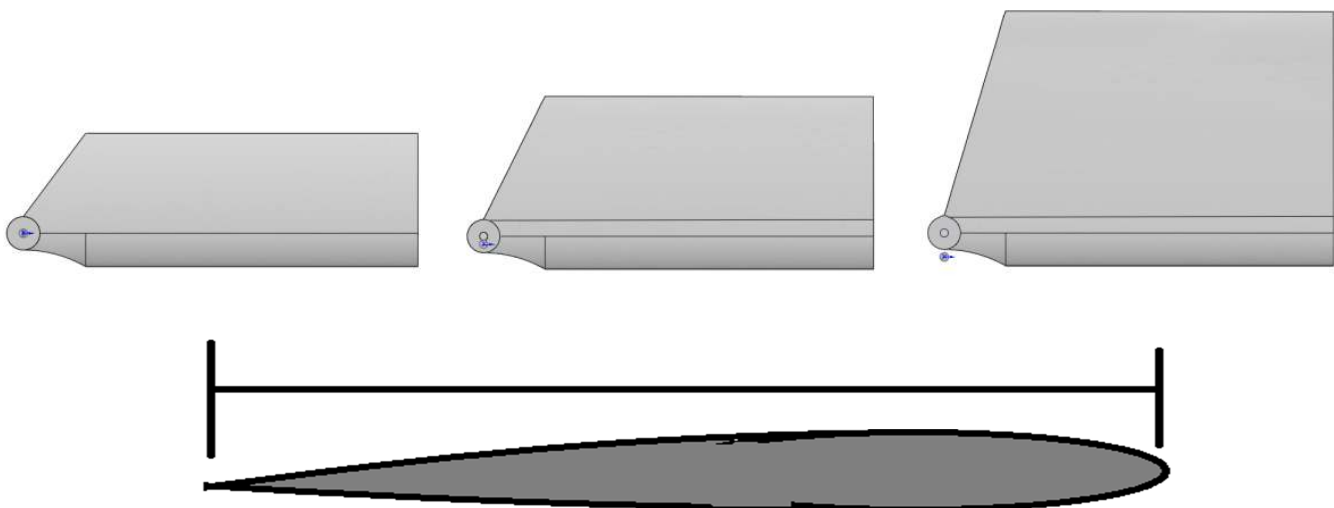

Figure 4: Propellers of varying Chord Lengths

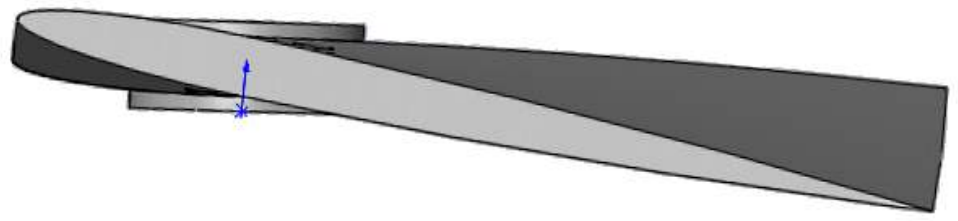

Figure 5: Propeller with a Linear Twist
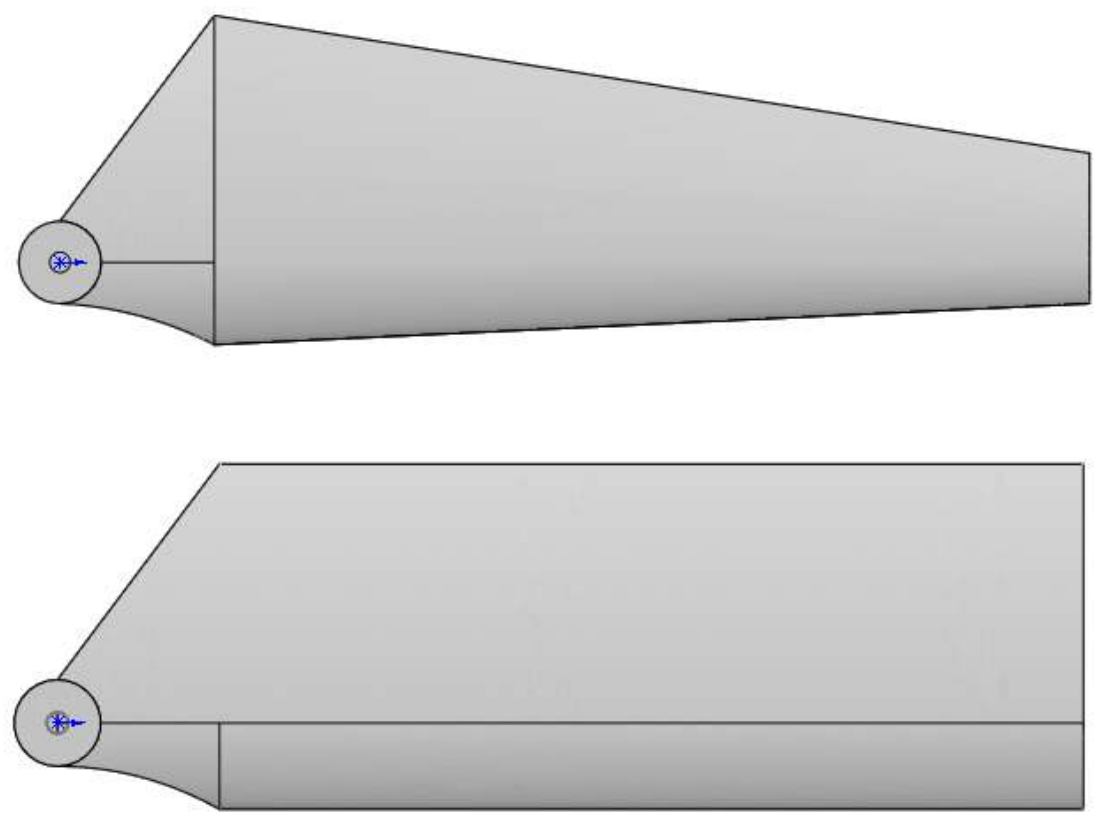

Figure 6: Propeller with a Linear Taper

Variables span, chord, twist, and taper ratio are shown in Figures 3, 4, 5, and 6 respectively. 


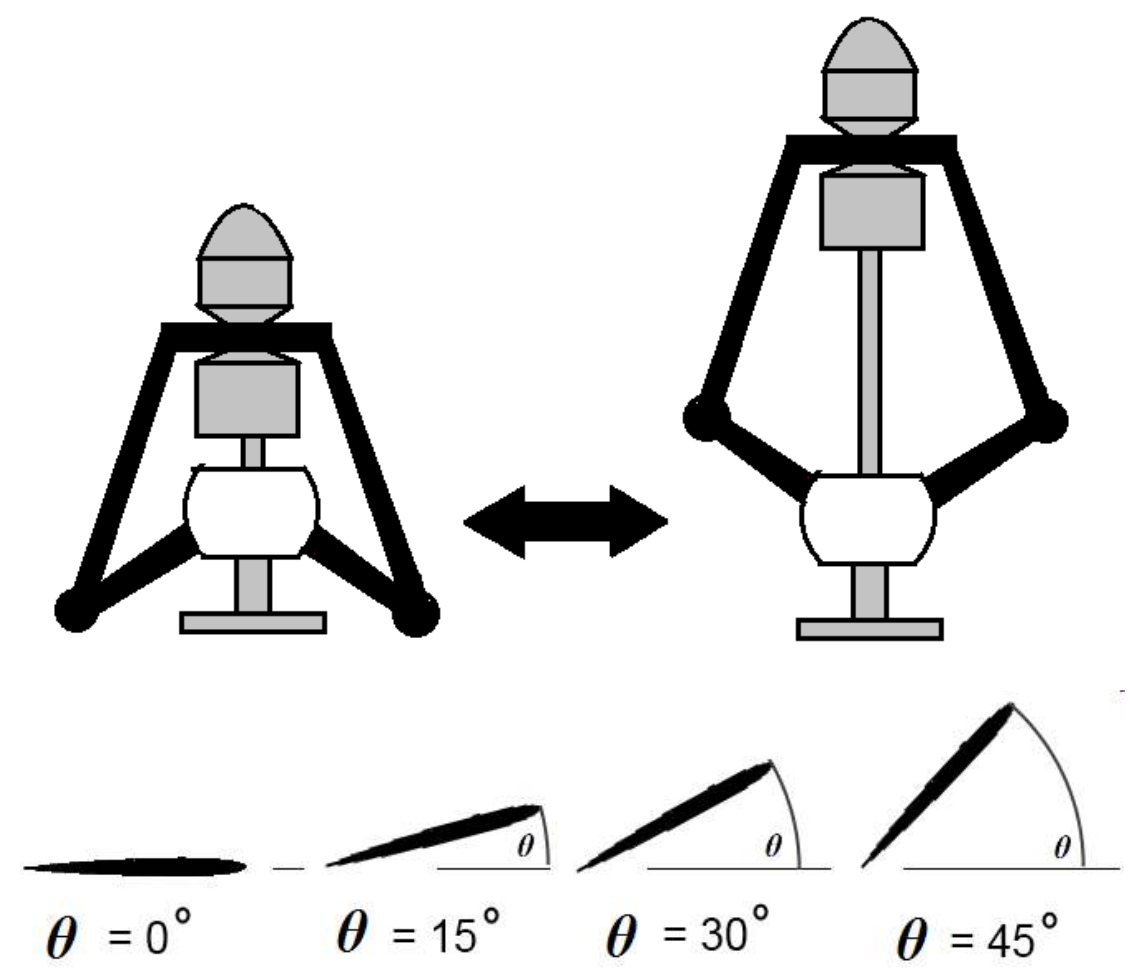

Figure 7: Propeller Pitch Motion

To control the pitching motion of the propeller, the mechanism designed is shown in Figure 7. A control arm is connected to the propeller shaft through a servo motor. The operator controls the amount of pitch using a control knob. The operator can also control the motor speed using a second control knob. This gives the operator control over all the six variables. The electrical setup includes an Electronic Speed Control (ESC), two tester controllers; one for controlling speed and the other for the propeller pitch, ac adapters to supply electrical power, servo motor to control pitch, and an electric motor to turn the propeller. The electrical setup is shown in Figure 8. Students also designed a few alternatives for the apparatus. A lever fulcrum balance design is shown in Figure 9. The motor and servo mount locations make the fulcrum design difficult to setup and operate. Figure 10 shows a simple propeller and motor mounting system on flat top digital scale. The scale only measures the downward force. Thrust (upward) force would not be readable on the scale. A few other approaches were proposed during the conceptual design stage. The final design is shown in Figure 12. The truck bed rolls on small ball-bearings. Guide rails keep the truck on the tracks and on a straight path. The propeller is surrounded by a light shroud. The propeller shroud is designed for operation safety. As the motor turns, the propeller generates thrust and pulls the truck bed on which it is mounted. Well-oiled ball-bearings minimize drag between the truck bed and the platform. The thrust force is measured on the digital scale. With this experiment, students can measure the maximum thrust a certain configuration of propeller generates at various speeds and pitch angles. By using different designs of the propellers, students can determine and understand the effect of various variables on the performance of the propellers. 


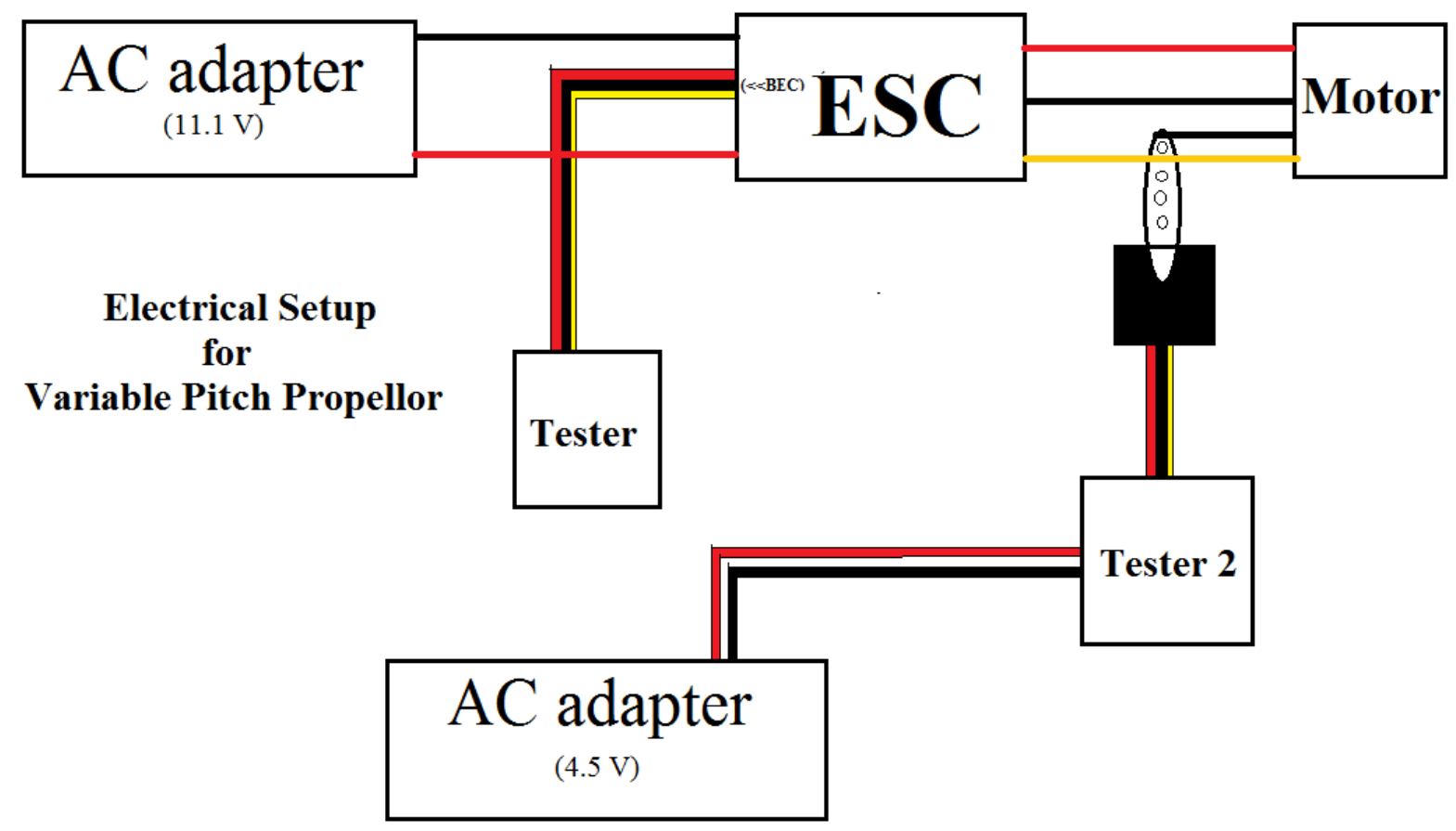

Figure 8: Electrical Setup

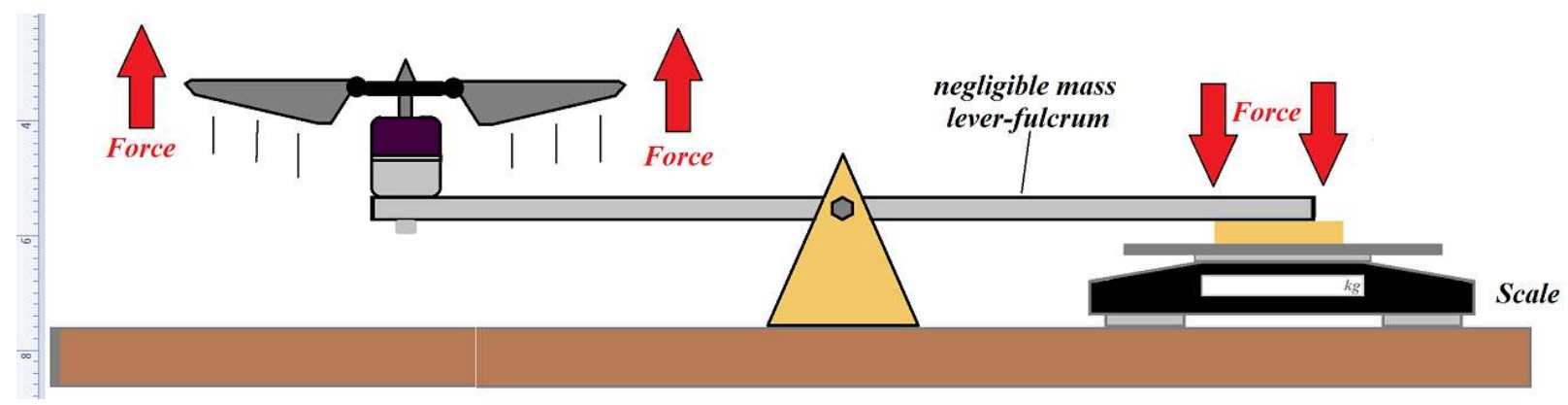

Figure 9: Alternative Design Approach 1

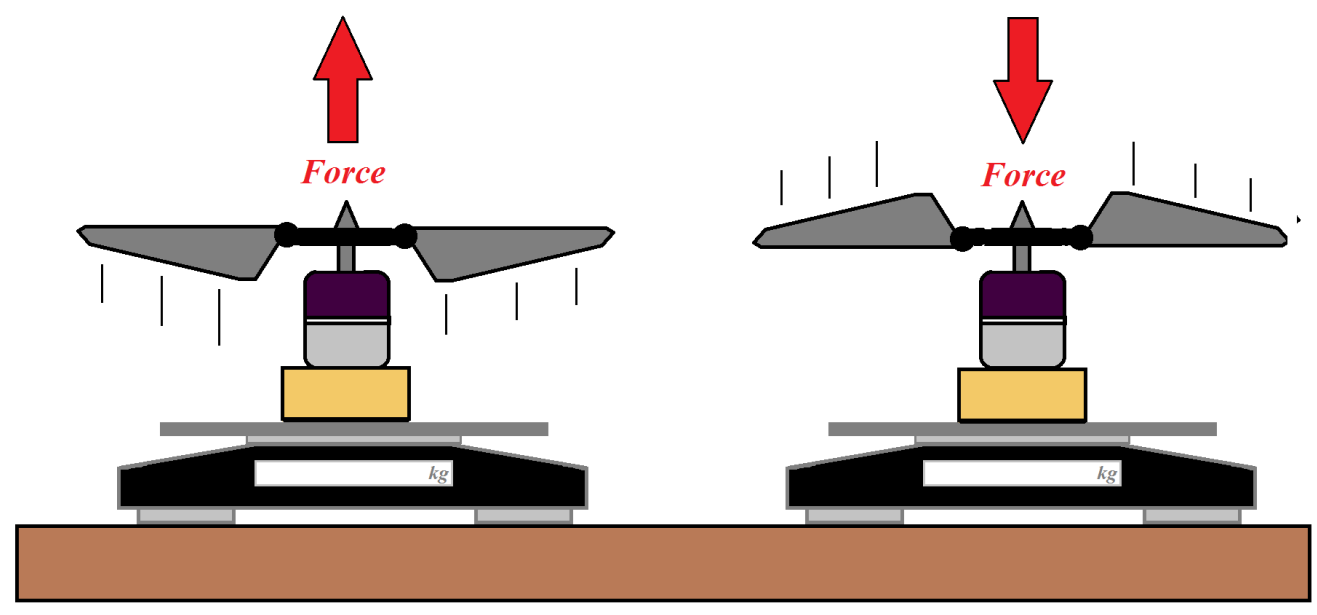

Figure 10: Alternative Design Approach 2 


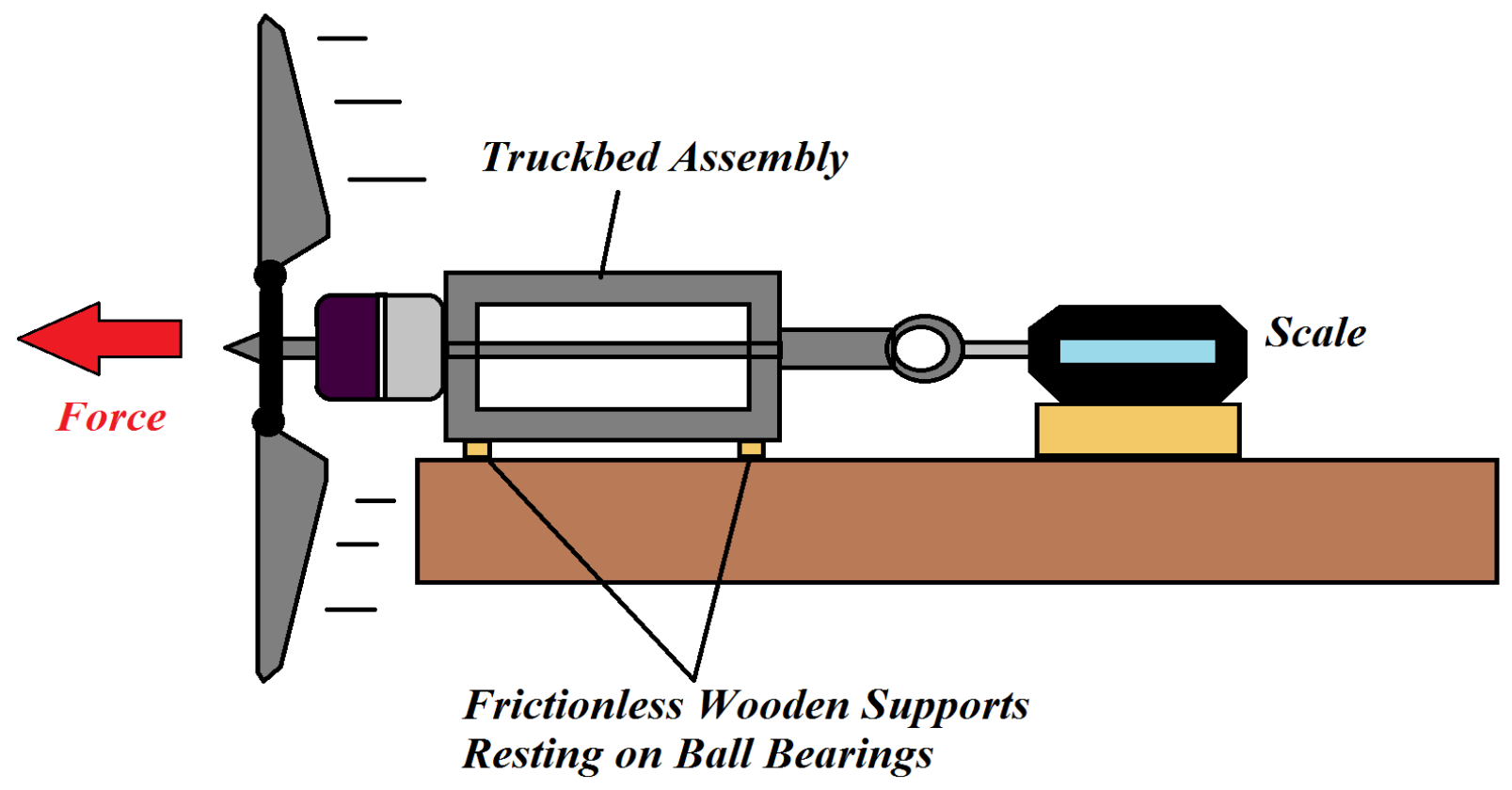

Figure 11: Final Thrust Measurement Apparatus Design Schematic

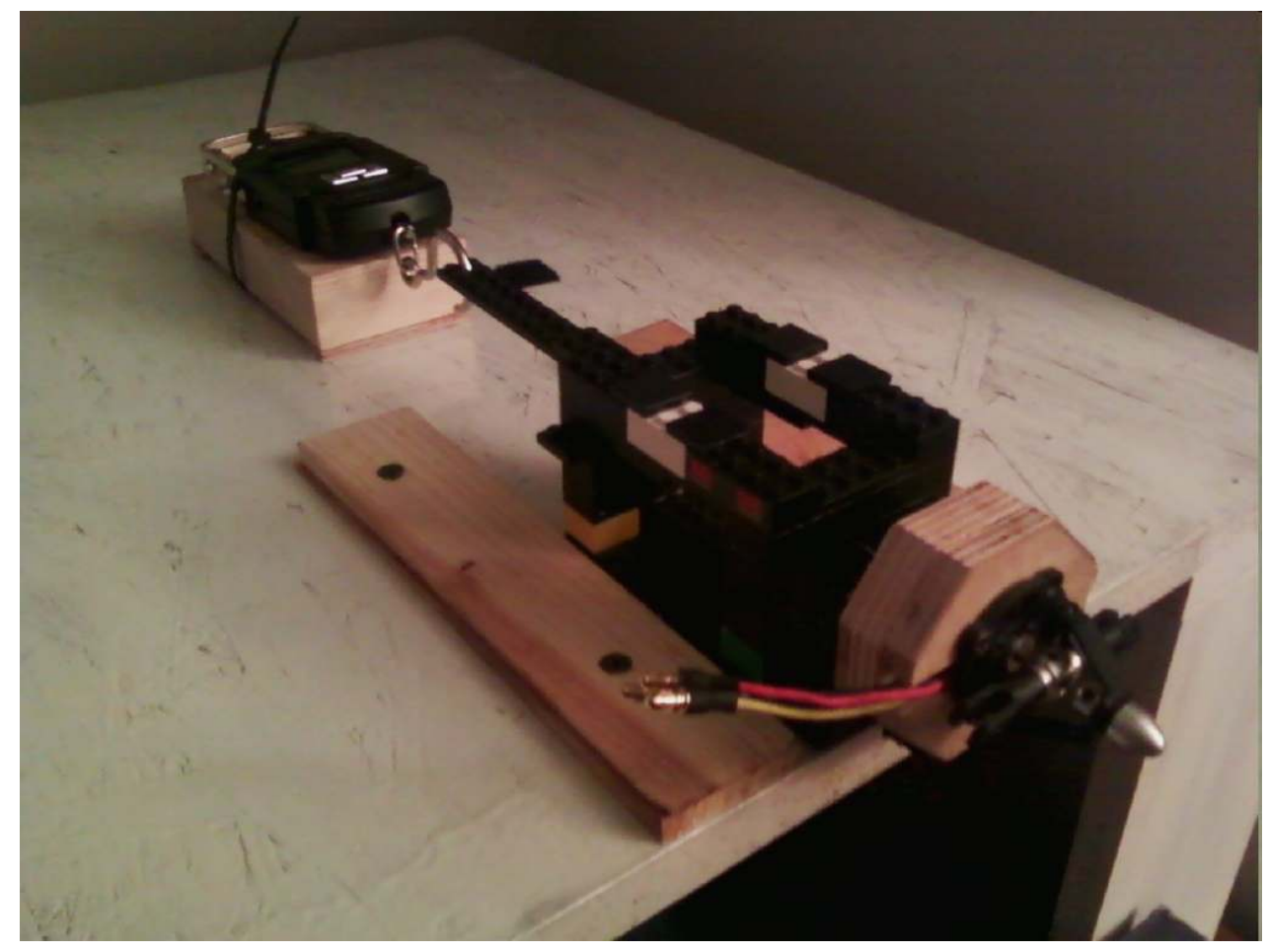

Figure 12: Complete Thrust Measurement Apparatus

One of the challenges of this project was to make the apparatus robust enough to be used in a laboratory environment. Since this was a student designed project, the current design needs several improvements before it can be safely used by other students in the aerospace laboratory. 
In addition to safely securing the propeller, the truck bed needs to be constructed out of robust and strong material which will keep it from breaking. The motor, scale, and propeller mounting mechanisms, need to be made more secure. The wiring needs to be concealed and the controllers need to be safely secured to the platform. In other words, the apparatus has to go through a few design iterations and improvements. The design, procurement of parts, building of the apparatus, and the tests provided the students a valuable learning experience.

\section{Future Improvements}

The next iteration of this problem is to improve the design and make it robust and reliable for the laboratory use. The intent is to have the second generation of students re-build the apparatus, collect and analyze data and report detailed results. The freestream velocity can also affect propeller's performance. An additional variable that can be added is the variable freestream velocity. A simple household fan can be used to simulate the variable speed freestream air. A laboratory manual will be generated for use as part of the Aerodynamics experiments.

\section{$\underline{\text { Conclusion }}$}

In this research project, undergraduate students were involved in the design and development of a variable pitch propeller based thrust measurement apparatus to be used in the Aerospace engineering laboratory at Southern Polytechnic State University. The undergraduate research helped the students in gaining theoretical and practical knowledge for conducting and completing research. Through various research activities as part of the Peach State LSAMP program, students learned and improved their ability to think critically, solve engineering problems, trouble-shoot, and better understand engineering principles. Our students presented the research at the Peach State LSAMP annual conference in Savannah, GA. Although the students have submitted their work, the apparatus needs to be improved and made more robust before it can be safely used in a laboratory environment.

\section{References}

1. 1. T. Goodwin, B. Holmes, 'Challenges of engaging in research with undergraduate students,' http://www.wvresearch.org/index.php, Last accessed on 10/4/11

2. Ann, Q. Gates, Patricia, J. Teller, Andrew Bernat, Nelly Delgado, 'Meeting the challenge of expanding participation in undergraduate research experience,' department of computer science, University of Texas at El Paso 
3. Sarah, S. Adams, 'Starting and maintaining an academic year undergraduate research program,' Mathematical association of America, http://www.maa.org/columns/resources/issue\%204.html, Last accessed on $10 / 4 / 11$

4. Janna, S. W., 'The Design of a Fluid Meter Apparatus for the Fluid Mechanics Laboratory,' Proceedings of 2011 ASEE Southeast Section Conference

5. Jang, S., Markowitz, K., 'Initiating the Undergraduate Research Study through NYC-LSAMP Summer Fellowship Program,' Proceedings of 2010 ASEE Southeast Section Conference

6. The Peach State Louis Stokes Alliance at Southern Polytechnic State University http://pslsamp.spsu.edu/index.html, last visited on Dec 7, 2011

7. Anderson, J., 'Introduction to Flight,' McGraw Hill Companies, 20011, ISBN: 0073380245

8. Butler, M. W., Terpenny, P. J., Goff, R. M., 'An Experiment in Learner - Centered Instruction in Aerospace Engineering capstone design, 2010 ASEE Southeast Section Conference

9. Sinha, A., 'High Altitude Student Ballooning Project: An Intensive Research Experience for Undergraduate Engineering Students, 2010 ASEE Southeast Conference 